\title{
Early Detection of At-Risk Undergraduate Students through Academic Performance Predictors
}

\author{
Vikash Rowtho ${ }^{1}$ \\ ${ }^{1}$ Charles Telfair Institute, Moka, Mauritius \\ Correspondence: Vikash Rowtho, Charles Telfair Institute, Telfair, Moka, Mauritius. Tel: 230-40-16-511. E-mail: \\ vikash.rowtho@telfair.ac.mu
}

Received: June 15, 2017

Accepted: June 22, 2017

Online Published: July 18, 2017

doi:10.5539/hes.v7n3p42

URL: http://doi.org/10.5539/hes.v7n3p42

\begin{abstract}
Undergraduate student dropout is gradually becoming a global problem and the 39 Small Islands Developing States (SIDS) are no exception to this trend. The purpose of this research was to develop a method that can be used for early detection of students who are at-risk of performing poorly in their undergraduate studies. A sample of 279 students participated in the study conducted in a Mauritian private tertiary academic institution. Results of regression analyses identified the variables having a significant influence on academic performance. These variables were used in a linear discriminant analysis where 74 percent of the students could be correctly classified into three categories: at-risk, pass or fail. In conclusion, this study has proposed a new technique that can be used by institutions to determine significant academic performance predictors and then identify at-risk students upon whom interventions can be implemented prior to exams to address the problem of dropouts.
\end{abstract}

Keywords: academic performance, dropout, early detection, undergraduate study

\section{Introduction}

Why would a student enrol on an undergraduate programme, pay the fees and spend time studying before eventually dropping out or being terminated from the course? This question, which seems to have no logical answer, was the starting point of this study which was conducted in a tertiary education institution, located in Mauritius which forms part of the thirty nine Small Island Development States (SIDS).

\subsection{Small Islands Developing States}

The concept of SIDS emerged in 1994 when the Barbados Programme of action was adopted by the United Nations which characterised SIDS as being countries facing similar challenges towards sustainable development due to their small size, remoteness, limited opportunities for the private sector and relying largely on their public sector amongst others (United Nations, 1994).

The Barbados Programme was followed by the Mauritius strategy of implementation in 2005 where one of the proposed strategies outlined in the report "Further Implementation of the Programme of Action for the Sustainable Development of Small Island Developing States" recommends the implementation of action plans to improve both access and quality of education (United Nations, 2005).

The Programme of Action for the Least Developed Countries for the Decade 2011-2020 adopted at the Fourth United Nations Conference on the Least Developed Countries held in Istanbul in 2011 reiterated the fact the importance of ensuring access and equity in education so that the least developed countries for sustainable development (United Nations, 2011).

More recently, during the third international conference on SIDS held in Samoa in 2014, the United Nations' SIDS Action Platform Document outlines that the people are the greatest resource to build resilient societies and economies and highlights the importance of education in their sustainable development (SIDS Action Platform, 2014).

\subsection{The Current Study}

In view of the above it is clear that education is vital for countries such as Mauritius as well as the other small island developing states to ensure their sustainable development. This is the reason why this study will be conducted in the context where it is not only crucial to provide access to education but where it is equally 
important to ensure that students complete their courses. In other words, completion rates are also an important factor in the strategy of using education for sustainable development.

Coming back to the initial question that was raised regarding students who drop out or are not able to complete their courses, a review of administrative records shows that every semester a number of students find themselves in situations where they have to either voluntarily or involuntarily put a stop to their studies. Although literature contains numerous studies on attrition, there have been no studies conducted in the context of Small Islands Developing States in which the determinants of academic performance are explored. If follows that there is no literature which explore whether SIDS face the same challenges as developed countries with regards to academic performance. Moreover there have been no recommendations to address issues related to poor academic performance.

This paper will seek to fill this gap by conducting a study that will assess the current situation in a private tertiary education institution and at the same time discuss the similarities and differences with developed countries so that further studies could be initiated both in Mauritius and in other small islands developing states. The findings may also enable policymakers both at institutional and notional levels to take appropriate measures in addressing issues with academic performance that eventually lead to non-completion of courses by undergraduate students.

\subsection{The Higher Education Landscape}

The higher education landscape in Mauritius is regulated by the Tertiary Education Commission (TEC) which controls both the public and private institutions. In fact, higher education was exclusively provided by public universities until recently, around two decades ago, when private institutions have started setting up on the island. Public universities are run from subsidies provided by the government, while private tertiary institutions are run from fees paid by students. This study has been conducted in a private institution based in Mauritius and that has been providing higher education to local students as well as foreigners for fifteen years. The institution is an offshore partner of an Australian University and it allows students to acquire an Australian qualification while studying in Mauritius, without having to travel overseas where the costs would have been prohibitive for the majority of them. Although the financing and partnership mechanisms differ, both public and private institutions face the same challenges with regards to student drop outs and non-completion of courses on which the students had initially enrolled.

\subsection{The Higher Education Challenges}

Understanding the reasons of non-completion can help in addressing the problem and as a result, increase the completion rates. This can make such models more sustainable and allow for replication in Mauritius and other parts of the world, in particular other small islands developing states, to promote education and to make it available to the maximum number of students. This could cater for a growing number of potential students who would otherwise find it impossible to access higher education either because of the high costs or limited access.

The statistics provided by the TEC, the regulator of tertiary education in Mauritius, show that the dropout rate in the two Mauritian public universities was above $10 \%$, whereas the corresponding figure for the institution where the study has been carried out was above $15 \%$. Additionally, according to official forecasts, the undergraduate enrolment rate in Mauritius is expected to increase by $300 \%$ over the next 10 years (Tertiary Education Strategic Plan, 2013). Should the current dropout rates prevail, the total number of students who do not complete their courses will proportionately increase if appropriate measures are not taken. Therefore, from an educational perspective, it is crucial to address the problem so that the impact of students not completing their studies is kept to the minimum level.

A review of the literature has shown that, no studies have investigated the influence of disengagement on academic performance in the context that also simultaneously includes cognitive and non-cognitive variables such as personality, attendance rate, gender, year of study, learning styles, Socio Economic Status (SES) and course of study especially in the context of Small Island Developing States. Therefore, the proposed model will attempt to determine the significance as well as the contribution of each of these predictors on academic performance which will be measured using Grade Point Average (GPA).

\subsection{Literature Review}

A description of the variables used in this study and a rationale for their inclusion are provided below.

\subsubsection{Academic Performance}

Some of the earliest publications in this research area are from the beginning of the last century, when Webb (1915) and Spearman (1927) proposed two factors, will (w) Webb (1915) and general intelligence (g) (Spearman, 
1927), as contributing factors to academic ability. Since then, numerous studies have examined the predictors of academic performance, which is usually measured by GPA. Flemming (1932) showed that personality and emotions were correlated with academic performance. Subsequently, some of the determinants of academic performance studied by other researchers are Intelligence (Laidra, Pullman, \& Allik, 2007; Chamorro-Premuzic \& Furnham, 2008); Personality (Komarraju, Karau, Schmeck, \& Avdic, 2011; Rosander, Backstrom, \& Stenberg, 2011); Personality traits, self-esteem, and self-efficacy beliefs (Di Giunta, Alessandri, Gerbino, Luengo, Zuffiano, \& Caprara, 2013); Educational persistence, motivational, and study skills indicators (Moreira, Dias, Vaz, \& Vaz, 2013); Extracurricular activities (Ackerman, Chamorro-Premuzic, \& Furnham, 2011); Gender (Furnham, Monsen, \& Ahmetoglu, 2009); Self-efficacy beliefs in self-regulated learning (Zuffianò, Alessandri, Gerbino, Luengo, Di Giunta, Milioni, \& Cappara, 2013); Learning styles (Entwistle, 2001; Cassidy, 2004; Vermunt \& Vermetten, 2004; Ng, Pinto, \& Williams, 2011); Socioeconomic status (SES) (Hauser, 1994; Sirin, 2005; Zuffianò et al., 2013); Gender differences (Carvalho, 2016); and Negative justice contact and school expulsion (Robison et al., 2017). In the current study, the dependant variable will be academic performance. It will be measured using GPA, which is the mean of the final results of the four units in which a student is enrolled for the semester. For the purposes of the analysis, because the pass level is $50 \%$ for any unit, a GPA score below $50 \%$ will be considered poor performance.

\subsubsection{Disengagement}

Disengagement from higher education may take various forms, such as withdrawal or involuntary termination from a course. Among the few studies conducted on disengagement, Brint and Cantwell (2012) draw on classic sociological work on conformity and deviance to theorise on four dimensions of academic disengagement in their "Portrait of the disengaged". Referring to the study conducted by Bean in 1985 that "analyses the relationship between academic, social and personal outcomes, and the intent to withdraw of college", L. Duque, J. Duque and Suriñach (2013) note that "personal outcomes is the best predictor of the college student dropout syndrome". Tinto used Durkheim's theory of suicide to develop a model that treats dropout as a process (Tinto, 1975). Drawing on the field of educational economics, Tinto (1975) postulated that disengagement leads to dropout, which has an effect on academic performance. The model also argues that continuance is directly related to the student's integration into the academic and social system of the institution. Taking the above factors into consideration, interviews were conducted with selected students and administrative staff. Archives, reports and other relevant documentation from the institution's administrative department were subsequently consulted after seeking permission from the relevant authorities. Following the interviews and consultation of archives, the reasons that led or could potentially lead to disengagement were recorded. The answers provided were then categorised by listing related items into the same group. Following this exercise, five groups that led to students' loss of interest in their courses emerged: unsuitable course selection, poor performance in continuous assessments, issues with lecturers, university environment (e.g., security level, use of technology, extent of extracurricular activities) and personal circumstances (including financial, health or other personal problems).

\subsubsection{Personality and Academic Performance}

The relationship between the Big Five personality traits-namely conscientiousness, openness, neuroticism, extraversion and agreeableness - and academic performance has been investigated by many researchers, namely, Busato, Prins, Elshout and Hamaker (2000), Komarraju et al. (2011), Ackerman, Chamorro-Premuzic, and Furnham (2011), Chamorro-Premuzic and Furnham (2008), O'Connor and Paunonen (2007), Heaven and Ciarrochi (2012), Rosander and Bäckström (2014), Vedel (2014) and Morris and Fritz (2015). Although there are variations in their findings, these studies generally agree that neuroticism, in contrast with conscientiousness, correlates negatively with academic performance. While replicating the experiments carried out in the US and Europe, this study will also attempt to determine whether the personality factors display the same characteristics in the small island developing states as in the US and in Europe. The Big Five Factor Markers from the International Personality Item Pool, developed by Goldberg (1992), are used in this study to measure the effects of extraversion, agreeableness, conscientiousness, neuroticism and openness on academic performance.

\subsubsection{Intelligence and Academic Performance}

A number of studies have shown that intelligence is almost always a major predictor of academic success (Chamorro-Premuzic \& Furnham, 2008; Busato et al., 2000; Kuncel, Hezlett, \& Ones, 2004). The only difference is the degree of influence that intelligence has on academic performance in these studies (Deary, Strand, Smith, \& Fernandes, 2007; Poropat, 2009; Lozano, Gordillo, \& Pérez, 2014). In their meta-analysis of previous studies, Von Stumm, Hell, and Chamorro-Premuzic (2011) concluded that "mental ability test scores 
are substantially correlated with academic performance". More recently, Soares, Lemos, Primi and Almeida (2015) studied the mediating role of prior academic achievement between intelligence and final academic achievement (Soares et al., 2015). In this case also, this study will try to determine whether intelligence has the same effect on academic performance in a SIDS context as compared to the results from publications in the US and Europe. The Wonderlic Personnel Test (WPT), which has been implemented in similar studies, for example Chamorro-Premuzic and Furnham (Chamorro-Premuzic \& Furnham, 2008), as an indicator of intelligence is used in this study to measure the impact of intelligence on academic performance.

\subsubsection{Learning Styles and Academic Performance}

Previous studies on the predictors of academic performance often make reference to learning styles, which many researchers have investigated with different outcomes (Entwistle, 2001; Vermunt \& Vermetten, 2004; Yip, 2012, 2013; Ng, Pinto, \& Williams, 2011; Cassidy, 2004). One such study was conducted by Boyle, Duffy, and Dunleavy (2003) from a British university to test whether Vermunt's integrated model of learning could be generalised. The results showed that the meaning-directed learning style had a low positive association with academic performance, whereas the undirected learning style had a low negative association with academic performance (Boyle, Duffy, \& Dunleavy, 2003). Other studies, for example Vanthournout et al. (2012) and Komarraju et al. (2012) have suggested that learning styles may influence academic performance. This research attempts to determine the extent to which learning styles influence academic performance in the current setup. Professor Vermunt, who devised the Inventory of Learning Styles (ILS) for higher education (Vermunt \& Vermetten, 2004), granted permission to use his 120 -item ILS for this study.

\subsubsection{Socioeconomic Status (SES) and Academic Performance}

The interviews conducted for this study suggested that students did not benefit from the same types of facilities, including access to technology and bank loans, most likely due to different SES. Exit interview records show that a number of students withdrew from their studies due to a lack of financial means. In this study, SES is included as a variable together with the other predictors to determine whether it has an effect on academic performance, as suggested by Komarraju et al. (2011), who recommended "examining environmental factors such as socioeconomic status as predictors of academic achievement". In his meta-analytic review of the literature, Sirin (2005) reported that the relationship between SES and academic achievement was inconsistent, ranging from a strong relationship to no correlation at all (Sirin, 2005). This study will try to determine the effect of SES in academic performance in a small island context.

\subsubsection{Attendance and Academic Performance}

After conducting interviews and consulting administrative records subsequent to obtaining relevant permissions, it was observed that students who withdrew from their programmes usually had a higher-than-average absenteeism rate. A review of the literature revealed that academic performance is closely related to attendance. These studies were conducted in various settings and, in many instances, in conjunction with other variables (Romer, 1993; Halpern, 2007; Credé, Roch, \& Kieszczynka, 2010). This study examines whether students' absenteeism rate influences their academic performance. This approach is in line with the suggestion by Komarraju et al. (2011) regarding future research on the predictors of academic achievement. In this study, the absenteeism rate will be computed as a percentage over the semester.

\subsubsection{Gender and Academic Performance}

In this case also, after seeking relevant permissions, a review of administrative records revealed that male students tend to withdraw from their studies more frequently than their female counterparts do. Previous studies have shown that gender and academic performance are linked (Farooq et al., 2011). In a study that used data from the University of Plymouth, Hoskins, Newstead, and Dennis (1997) showed that gender was related to academic performance. Similarly, Nyikahadzoi et al. (2013) showed that gender was significantly correlated with academic performance in Zimbabwe. The influence of gender on the academic performance of students is investigated in this study, and gender is categorised as male or female. The results might shed some light on the tendency in the small islands context.

\subsubsection{Year f Study and Academic Performance}

The administrative records showed that students are more likely to withdraw from their studies in their first year; in the past 15 years, approximately $50 \%$ of students who withdrew were in their first year of study. This observation is in line with the findings of Komarraju, Ramsey, and Rinella (2013), who argued that the existence of higher education institutions is linked to students' successful completion of their first year and their 
continuation to graduation. The year of study, which is categorised as year 1 , year 2 or year 3 , is used to determine whether it influences students' academic performance.

\subsubsection{Selected Course and Academic Performance}

The interviews revealed that many students who selected the wrong course performed poorly in their studies. This poor performance led to a gradual disengagement from their course and, in some cases, may have led to withdrawal or termination from their course. This study examines whether the selected course has an impact on students' academic performance. The courses are categorised as Bachelor of Commerce (B Com) or Bachelor of Arts (BA). Performance is measured using students' GPA when the end-of-semester results are issued.

\section{Method}

\subsection{Participants}

The target population for this study consisted of a total of 1014 students enrolled in the Bachelor of Commerce (B Com) and Bachelor of Arts (BA) degree programmes during the second semester of 2014. A total of 774 students enrolled in a B Com degree programme, whereas 240 students enrolled in the BA degree programme. Of these students, 327 were in their first year of study, 296 were in their second year, and 391 were in their third year. With regard to gender, the population comprised 467 male and 547 female students.

\subsection{Procedures}

Since the current study is proposing to evaluate the contribution of academic performance predictors, correlation analysis will first be performed. This will give an idea of the strength and direction of the association between the independent and dependant variables. Then, a series of three regression analyses will be run. The first regression will determine the individual and overall effects of known and documented independent variables on academic performance. A second regression will be run to assess the influence of a set of five variables which have been designed to measure five dimensions of student disengagement on academic performance in a previous study. The third regression analysis will include all predictors from the first and second models to determine the combined effect of the two sets of variables.

A sample of 279 students was selected using stratified random sampling. Selected students were asked to complete a survey questionnaire one month prior to their 2014 second semester exams. They were contacted through email, which explained the purpose and importance of the survey and emphasised the voluntary nature of the exercise and the confidentiality of their responses and Intelligence Quotient (IQ) scores. The questionnaires were then inserted in individual envelopes and distributed to the students in class by their respective lecturers who, after being briefed, provided the students with instructions for completing and returning the questionnaires.

The following week, the completed questionnaires were collected, the data were entered into SPSS, and the scoring keys for the various scales were used to perform the required calculations. The participants then took the Wonderlic Online WPT-R test to measure their IQ. These cognitive ability tests were purchased from Wonderlic and set up in the institution's library. The librarian and related staff were briefed on how to conduct the tests. It was ensured that all workstations were located in the same area so that the students could take the tests under identical conditions.

Finally, given that this study is directly related to performance, the GPA of the students was collected at the end of the semester after the release of the results after obtaining relevant permissions. Each student was enrolled in four study units for which the pass mark was $50 \%$. GPA was calculated by taking the mean of their individual unit scores for the semester. Data for the absenteeism rate, gender, year and course were obtained from the institutional administrative records after permission was sought from the participating students and the institution.

\subsection{Measures}

The survey questionnaire consisted of five sections that measured Personality, Learning Styles, Socioeconomic Status, Disengagement and the retrieved Demographic Data. Section one of the questionnaire measured the Big Five personality traits using the Big Five Factor Markers from the International Personality Item Pool, which was developed by Goldberg (1992). The 50 items were measured using a 5-point Likert-type scale, which is available in the public domain, to measure the five aspects of personality, namely, Extraversion, Conscientiousness, Neuroticism, Openness and Agreeableness. The Cronbach's alpha values for the subscales ranged from 0.702 to 0.738 , which is indicative of internal consistency. These values were fairly consistent with the values listed in the International Personality Item Pool (IPIP) website, which range from 0.77 to 0.86 . 
Section two of the questionnaire measured the students' level of disengagement from their course using the Disengagement scale developed for this study, which consists of 104 questions measured on a five-point Likert scale. Participants rated their levels of disengagement with respect to their university environment, lecturers, personal issues, choice of course and performance on continuous assessment tasks. Their total disengagement was obtained by adding the disengagement scores obtained for the various factors, for which the Cronbach Alpha values ranged from 0.905 to 0.945 .

Section three used a 120-item inventory of learning styles for higher education, also measured on a 5-point Likert-type scale, which was developed by Prof. Jan Vermunt in 1994 with a view to gain clearer insight into how students go about their studies and how they perceive their own learning. Permission was obtained from Prof. Vermunt to use his scale in the context of this study, which generated Cronbach's alpha values ranging from 0.638 to 0.823 .

Section four of the questionnaire consisted of 10 questions to assess the socioeconomic status of the student's family. Section five of the questionnaire collected the students' demographic data. After data collection, data entry and data cleansing, the analysis was carried out using SPSS version 21.

\section{Results}

An exploratory factor analysis was conducted to identify the underlying SES factors. The Kaiser method in SPSS via the Principal Components Analysis (PCA) with varimax rotation was in line with the parallel analysis (Monte-Carlo simulation) and confirmed that the actual number of factors was four: Occupational and income indicators, Wealth indicators, Level of education of parents, and Type of accommodation.

\subsection{Correlation Analysis}

The next step was to run a correlation analysis with all the predictors to determine the extent of the relationship between the factors to detect any possible multicollinearity before subsequently running a multiple regression analysis. The results show that course and the personality construct agreeableness are significantly correlated with academic performance at 5\% significance level. Furthermore, at $1 \%$ level, academic performance was significantly correlated with, gender, absences, IQ, the personality factors extraversion, conscientiousness and neuroticism, course selection, performance, lecturers, university environment, personal circumstances and finally application directed learning style.

\subsection{Regression-Model 1}

After ensuring that the assumptions for running a multiple linear regression were met, SPSS was used to run the test. The results indicate that the regression model was valid in terms of predictability $\left(F\left(\begin{array}{l}6 \\ 223\end{array}\right)=47.871\right.$, $p<0.001)$. Stepwise regression, in the model summary showed that the predictors explained a large amount of the shared variance with the dependent variable $\left(R^{2}=.563, R_{\text {Adjusted }}^{2}=.551\right)$.

Table 1. Coefficients ${ }^{\mathrm{a}}$ for Model 1

\begin{tabular}{|c|c|c|c|c|c|}
\hline \multirow{2}{*}{ Model } & \multicolumn{2}{|c|}{ Unstandardised Coefficients } & \multirow{2}{*}{$\frac{\text { Standardised Coefficients }}{\text { Beta }}$} & \multirow{2}{*}{$\mathrm{t}$} & \multirow{2}{*}{ Sig. } \\
\hline & $\mathrm{B}$ & Std. Error & & & \\
\hline (Constant) & 14.848 & 5.004 & & 2.967 & .003 \\
\hline IQ & .455 & .036 & .584 & 12.463 & .000 \\
\hline Absences $(\%)$ & -.072 & .022 & -.158 & -3.339 & .001 \\
\hline Gender & 2.588 & .764 & .151 & 3.386 & .001 \\
\hline Year of study & 1.216 & .466 & .119 & 2.609 & .010 \\
\hline Neuroticism & -.414 & .094 & -.196 & -4.407 & .000 \\
\hline Conscientiousness & .549 & .160 & .159 & 3.425 & .001 \\
\hline
\end{tabular}

The coefficients displayed in Table 1 also showed that IQ $(\beta=.584, t(277)=12.463, p<.05)$, absences $(\%)$ $(\beta=-.158, t(277)=-3.339, p<.001)$, gender $(\beta=.151, t(277)=3.386, p<.05)$, year of study $(\beta=.119, t(277)=2.609$, $p<.05)$, neuroticism $(\beta=-.196, t(277)=-4.407, p<.001)$, and conscientiousness $(\beta=.159, t(277)=3.425, p<.01)$, were all significant predictors of GPA. Furthermore, the value of R square shows that the variables explain 56.3 
percent of the variance in GPA. These results suggest that IQ, gender, year of study and conscientiousness have a positive influence on academic performance while absences and neuroticism have a negative effect. IQ has the most influence followed by neuroticism, conscientiousness, absences, gender and year of study.

\subsection{Regression-Model 2}

Since a scale had been developed to measure the level of disengagement within the five identified areas, a second regression was run to assess the impact on academic performance by the disengagement components. Thus, the latter were included as predictors in a new model. A stepwise regression was run after ensuring that all the assumptions were met. The results from SPSS indicate that the regression model was valid in terms of predictability $(F(4272)=26.678, p<0.001)$. The results showed that the predictors explained a significant amount of the shared variance with the dependent variable $\left(R^{2}=.282, R_{\text {Adjusted }}^{2} .271\right)$. The coefficients in Table 2 show that personal circumstances $(\beta=-.319, t(277)=-5.675, p<.001)$, performance $(\beta=-.223, t(277)=-3.988$, $p<.001)$, course selection $(\beta=-.174, t(277)=-3.092, p<.01)$ and university environment $(\beta=-.134, t(277)=-2.388$, $p<.05)$ were all significant predictors of GPA.

Table 2. Coefficients ${ }^{\mathrm{a}}$ for Model 2

\begin{tabular}{|c|c|c|c|c|c|}
\hline \multirow{2}{*}{ Model } & \multicolumn{2}{|c|}{ Unstandardised Coefficients } & \multirow{2}{*}{$\frac{\text { Standardised Coefficients }}{\text { Beta }}$} & \multirow{2}{*}{$t$} & \multirow{2}{*}{ Sig. } \\
\hline & $B$ & Std. Error & & & \\
\hline (Constant) & 94.727 & 3.191 & & 29.689 & .000 \\
\hline Personal circumstances & -.127 & .022 & -.319 & -5.675 & .000 \\
\hline Performance & -.112 & .028 & -.223 & -3.988 & .000 \\
\hline Course selection & -.095 & .031 & -.174 & -3.092 & .002 \\
\hline University environment & -.088 & .038 & -.134 & -2.338 & .020 \\
\hline
\end{tabular}

After establishing that the disengagement variables have an impact on GPA, the next step was to assess a new model with predictors from the two above models as independent variables. This was tested using Model 3.

\subsection{Regression-Model 3}

From the above, since disengagement variables alone seem to have a significant effect on GPA, a third regression model was run with all the predictors from Models 1 and 2.

Prior to running this test, it was ensured that the assumptions of normality, homoscedasticity, multicollinearity and linear relationship between dependant and independent variables, were met. The results from SPSS indicated that the regression model was valid in terms of predictability $(F(8222)=41.065, p<0.001)$. Stepwise regression, showed that the predictors explained a large amount of the shared variance with the dependent variable $\left(R^{2}=.597\right.$, $\left.R_{\text {Adjusted }}^{2}=.582\right)$. The coefficients presented in Table 3 showed IQ $(\beta=.497, t(277)=10.585, p<.001)$, personal circumstances $(\beta=-.175, t(277)=-3.682, p<.001)$, neuroticism $(\beta=-.206, t(277)=-4.801, p<.001)$, gender $(\beta=.138$, $t(277)=3.188, p<.01)$, conscientiousness $(\beta=.145, t(322)=3.227, p<.01)$, absences $(\beta=-.139, t(322)=-3.022$, $p<.01)$, university environment $(\beta=-.110, t(322)=-2.318, p<.05)$ and year of study $(\beta=.093, t(322)=2.115, p<.05)$ were all significant predictors of GPA.

Table 3. Coefficients ${ }^{\mathrm{a}}$ for Model 3

\begin{tabular}{|c|c|c|c|c|c|}
\hline \multirow{2}{*}{ Model } & \multicolumn{2}{|c|}{ Unstandardised Coefficients } & \multirow{2}{*}{$\frac{\text { Standardised Coefficients }}{\text { Beta }}$} & \multirow{2}{*}{$\mathrm{t}$} & \multirow{2}{*}{ Sig. } \\
\hline & B & Std. Error & & & \\
\hline (Constant) & 33.626 & 5.873 & & 5.726 & .000 \\
\hline IQ & .392 & .037 & .497 & 10.585 & .000 \\
\hline Personal circumstances & -.072 & .020 & -.175 & -3.682 & .000 \\
\hline Neuroticism & -.439 & .091 & -.206 & -4.801 & .000 \\
\hline Gender & 2.384 & .748 & .138 & 3.188 & .002 \\
\hline
\end{tabular}




\begin{tabular}{|c|c|c|c|c|c|}
\hline Conscientiousness & .506 & .157 & .145 & 3.227 & .001 \\
\hline Absences (\%) & -.064 & .021 & -.139 & -3.022 & .003 \\
\hline University environment & -.075 & .033 & -.110 & -2.318 & .021 \\
\hline Year of study & .961 & .454 & .093 & 2.115 & .036 \\
\hline
\end{tabular}

Now that the significant predictors have been identified, the next step consists in using these variables to place the students into three categories: pass, fail or at-risk. This will be achieved using linear discriminant analysis.

\subsection{Linear Discriminant Analysis}

The linear discriminant analysis was conducted to determine whether eight independent variables, namely gender, IQ, year of study, absenteeism rate, conscientiousness, neuroticism, university environment and personal circumstances could predict student status, classified into three groups, according to their GPA, as "fail", "at risk" and "pass". Wilks' Lambda indicated that, overall, the predictors significantly differentiated among the three categories of student status $(\Lambda=320, \chi 2(16, \mathrm{~N}=279)=310.860, \mathrm{p}<0.001)$. Furthermore, the residual Wilks' Lambda was also significant $\left(\Lambda=.760, \chi^{2}(7, \mathrm{~N}=279)=310.860, \mathrm{p}<0.001\right)$. These test results indicated that the predictors differentiated among the three categories of student status after partialling out the effects of the first discriminant function, thus suggesting that both discriminant functions could be interpreted. Based on the within-groups correlation coefficients between the predictors and the discriminant functions, IQ had the strongest relationship with the first function while neuroticism had the strongest relationship with the second. Thus, the two discriminant functions were named as IQ and neuroticism respectively.

The means (group centroids) of the discriminant functions were consistent with the above interpretation since "fail", "at risk" and "pass" had respective means of $-1.439,0.353$ and 1.587. 75.6 percent of cases were correctly classified in a sample of 279 students, while a good Kappa coefficient of 0.628 showed that predictions were better than chance-level. Finally, cross-validation via the "leave-one-out" method, indicated that prediction in a new sample by the use of the discriminant function $\mathrm{D}=-6.586+0.092$ (IQ) -0.011 (personal circumstances) 0.034 (neuroticism) +0.427 (gender) +0.119 (conscientiousness) - 0.017 (absences) - 0.014 (university environment) +0.153 (year of study) would correctly classify 73.5 percent of cases.

\section{Discussions}

\subsection{Regression-Model 1}

In Model 1, although variables such as extraversion, agreeableness, application-directed learning style and course had significant correlations with academic performance, they were not significant in the regression model. These results are in line with the findings of Busato et al., in which no positive association between meaning-directed, reproduction-directed and application-directed learning styles and academic success could be established (Busato et al., 2000). These results are in line with Poropat (2009) whose meta-analysis showed the roles of intelligence and personality factors on academic performance at tertiary level. Literature also showed that attendance impacted on academic performance (Romer, 1993; Chen \& Lin, 2008; Schmulian \& Coetzee, 2011). These findings are very much in line with the literature, in which IQ had the largest contribution (Rosander \& Bäckström, 2012; Chamorro-Premuzic \& Furnham, 2008; Rosander, Bäckström, \& Stenberg, 2011; Deary et al., 2007).

\subsection{Regression-Model 2}

In Model 2, the coefficients of all four independent variables were negative, meaning that any increase would lower the value of academic performance. It should also be noted that personal circumstances had a higher influence followed by performance, course selection and finally university environment. These are in line with Bean (1985) whose student socialisation model included social, academic and personal outcomes in relation to the intention of dropping out. Furthermore, Edel (2003) suggested that poor academic achievement was the reason for dropping out. The results showed that the variable "lecturers" was excluded from the model. This may be because in the current setup, the local institution was required to deliver the courses in similar way as the academic partner. One of the mechanisms to ensure this takes place is the provision of training to all lecturers on the teaching principles to which they need to adhere. Additionally, all local lecturers are in constant contact with a unit coordinator from the partner institution, where instructions are given and information is shared throughout the semester. Moreover, the course syllabus is prescriptive, and all lecturers undergo training to teach as per the 
provider's rules, thus "absorbing" the importance of lecturers. In their study, Goel and Yang found that if there is a strong tie between the recipient and source in the transfer of knowledge, i.e., between the lecturer and student, the transfer of knowledge happens more smoothly (Goel \& Yang, 2015). They also recommend that European lecturers look for closer interaction with the students. In view of the contradictory findings, this is an area that offers room for future research, especially in different setups such as in public institutions or different island states.

\subsection{Regression-Model 3}

In Model 3, the results show that only two of the disengagement variables are significant in the new model: personal circumstances and university environment. Moreover, they are still negatively related to academic performance with personal circumstances having a greater influence than university environment. The results also show that neuroticism and absences are also negatively related to academic performance. IQ, gender, conscientiousness and year of study all have positive coefficients with IQ still having the largest influence on academic performance. These results are in line with Schmulian and Coetzee (2011) with regards to the relation between attendance and academic performance. Similarly to Rosander et al. (2011) the results suggest that gender might have an influence on academic performance. As suggested by Komarraju et al. (2013), year of study has turned out to be a significant predictor. Once again, it seems that the primary reason that students become disengaged from their studies is largely related to personal circumstances. In addition to the possible reasons mentioned earlier, the medium of instruction (i.e., people with French-language backgrounds having difficulty adapting to lectures delivered in English) may compound personal issues. In hindsight, one may find that personal circumstances encompass transportation problems and financial difficulties, with the latter affecting factors such as inadequate access to technology in terms of hardware and/or software or even Internet access in the home. Furthermore, because the institution is private and the students are fee-paying, many students may disengage due to unexpected financial difficulties. In addition to family lifestyle, personal issues may be related to the fact that some students lack certain important and necessary skills to achieve success, such as time management or communication skills. The reasons for the impact of the university environment on academic performance may be attributed to the needs and requirements of students for a change in infrastructure, especially with the growing demand for technological support, such as free and faster broadband access, power outlets to charge their devices, security issues on campus and the availability of healthy food in the canteen.

\subsection{Linear Discriminant Analysis}

Moreover, the linear discriminant analysis has correctly predicted the results of 74 percent of students with data collected one month prior to the exams by categorising them into three categories: pass, fail and at-risk. This outcome can therefore enable institutions to propose and implement personalised reintegration plans to assist at-risk students to remain enrolled instead of leaving the system. The outcome of this study, may also enable policymakers to legislate so that the principles of access and equity are transformed into reality.

\subsection{Conclusion}

Although the results shows that intelligence has a strong influence on GPA, other factors, such as conscientiousness, neuroticism, gender, year of study and absenteeism rate also contribute to determining the final outcomes of the students. In addition to the initial model, which accounts for $56.3 \%$ of the variance in GPA, these results are consistent with the findings of previous studies. When the five disengagement components (course selection, performance, lecturers, university environment and personal circumstances, all of which have significant negative correlations with GPA) were included in the initial model, a multiple regression using all other cognitive and non-cognitive predictors showed that only two of these-personal circumstances and university environment - significantly impacted GPA with the variance in GPA increasing to 59.7. The findings therefore show that the inclusion of the disengagement variables in the initial model increased its predictability by $3.4 \%$. By proposing a model that includes cognitive and non-cognitive predictors, this study offers a new perspective on student the determinants of academic performance in the context of a small island developing state. The regression analysis identified significant variables that can be used to clearly define areas in which students are at risk of becoming disengaged and thus discontinuing their studies.

The main limitation of this study is the fact that it was a cross-sectional research instead of a longitudinal one. Future research could consider testing the model in different kinds of institutions to verify the significance of each predictor in their respective setups. Longitudinal studies using this technique are also an area where future researchers could focus. With regards to future research directions, since IQ accounts for a large variability in GPA, Structural Equation Modelling (SEM) could be used to find any mediating effects of IQ with regards to academic performance. The outcomes would enable institutions to better understand the determinants of GPA 
and consequently enable them to take a more focused approach to address performance related problems and hence address the issue of dropouts related to academic performance.

\section{References}

Ackerman, P. L., Chamorro-Premuzic, T., \& Furnham, A. (2011). Trait Complexes and Academic Achievement: Old and New Ways of Examining Personality in Educational Contexts. British Journal of Educational Psychology, 81(1), 27-40. https://doi.org/10.1348/000709910X522564

Boyle, E. A., Duffy, T., \& Dunleavy, K. (2003). Learning Styles and Academic Outcome: The Validity and Utility of Vermunt's Inventory of Learning Styles in a British Higher Education Setting. British Journal of Educational Psychology, 73(2), 267-290. https://doi.org/10.1348/00070990360626976

Brint, C. S., \& Cantwell, A. M. (2012). Portrait of the Disengaged. In SERU Project and Consortium Research Paper (pp. 1-18). Berkeley: University of California. Retrieved from http://www.cshe.berkeley.edu/sites/default/files/shared/publications/docs/ROPS.Brint\&Cantwell.Disengage d.6.11.2012.pdf

Busato, V. V., Prins, F. J., Elshout, J. J., \& Hamaker, C. (2000). Intellectual Ability, Learning Style, Personality, Achievement Motivation and Academic Success of Psychology Students in Higher Education. Personality and Individual Differences, 29(6), 1057-1068. https://doi.org/10.1016/S0191-8869(99)00253-6

Carvalho, R. G. G. (2016). Gender differences in academic achievement: The mediating role of personality. Personality and Individual Differences, 94, 54-58. https://doi.org/10.1016/j.paid.2016.01.011

Cassidy, S. (2004). Learning Styles: An Overview of Theories, Models, and Measures. Educational Psychology, 24(4), 419-444. https://doi.org/10.1080/0144341042000228834

Chamorro-Premuzic, T., \& Furnham, A. (2008). Personality, Intelligence and Approaches to Learning as Predictors of Academic Performance. Personality and Individual Differences, 44(7), 1596-1603. https://doi.org/10.1016/j.paid.2008.01.003

Chamorro-Premuzic, T., \& Furnham, A. (2009). Mainly Openness: The Relationship between the Big Five Personality Traits and Learning Approaches. Learning and Individual Differences, 19(4), 524-529. https://doi.org/10.1016/j.lindif.2009.06.004

Credé, M., Roch, S. G., \& Kieszczynka, U. M. (2010). Class Attendance in College: A Meta-Analytic Review of the Relationship of Class Attendance with Grades and Student Characteristics. Review of Educational Research, 80(2), 272-295. https://doi.org/10.3102/0034654310362998

Dao, M. T. N., \& Thorpe, A. (2015). What factors influence Vietnamese students' choice of university? International Journal of Educational Management, 29(5), 666-681. https://doi.org/10.1108/IJEM-08-2014-0110

Deary, I. J., Strand, S., Smith, P., \& Fernandes, C. (2007). Intelligence and Educational Achievement. Intelligence, 35(1), 13-21. https://doi.org/10.1016/j.intell.2006.02.001

Di Giunta, L., Alessandri, G., Gerbino, M., Kanacri, P. L., Zuffiano, A., \& Caprara, G. V. (2013). The Determinants of Scholastic Achievement: The Contribution of Personality Traits, Self-Esteem, and Academic Self-Efficacy. Learning and Individual Differences, 27(2013), 102-108. https://doi.org/10.1016/j.lindif.2013.07.006

Duque, L. C., Duque, J. C., \& Suriñach, J. (2013). Learning Outcomes and Dropout Intentions: An Analytical Model for Spanish Universities. Educational Studies, 39(3), 261-284. https://doi.org/10.1080/03055698.2012.724353

Entwistle, N. (2001). Styles of Learning and Approaches to Studying in Higher Education. Kybernetes, 30(5/6), 593-603. https://doi.org/10.1108/03684920110391823

Farooq, M. S., Chaudhry, A. H., Shafiq, M., \& Berhanu, G. (2011). Factors Affecting Students' Quality of Academic Performance: A Case of Secondary School Level. Journal of Quality and Technology Management, 7(2), 1-14.

Flemming, E. G. (1932). College Achievement, Intelligence, Personality, and Emotion. Journal of Applied Psychology, 16(6), 668-674. https://doi.org/10.1037/h0072176 
Furnham, A., Monsen, J., \& Ahmetoglu, G. (2009). Typical Intellectual Engagement, Big Five Personality Traits, Approaches to Learning and Cognitive Ability Predictors of Academic Performance. British Journal of Educational Psychology, 79(Pt 4), 769-782. https://doi.org/10.1348/978185409X412147

Goldberg, L. R. (1992). The Development of Markers for the Big-five Factor Structure. Psychological Assessment, 4(1), 26-42. https://doi.org/10.1037/1040-3590.4.1.26

Halpern, N. (2007). The Impact of Attendance and Student Characteristics on Academic Achievement: Findings from an Undergraduate Business Management Module. Journal of Further and Higher Education, 31(4), 335-349. https://doi.org/10.1080/03098770701626017

Hauser, R. M. (1994). Measuring Socioeconomic Status in Studies of Child Development. Child Development, 65(6), 1541-1545. https://doi.org/10.2307/1131279

Heaven, P. C. L., \& Ciarrochi, J. (2012). When IQ is not Everything: Intelligence, Personality and Academic Performance at School. Personality and Individual Differences, 53(4), 518-522. https://doi.org/10.1016/j.paid.2012.04.024

Hoskins, S. L., Newstead, S. E., \& Dennis, I. (1997). Degree Performance as a Function of Age, Gender, Prior Qualifications and Discipline Studied. Assessment \& Evaluation in Higher Education, 22(3), 317-328. https://doi.org/10.1080/0260293970220305

Komarraju, M., Karau, S. J., Schmeck, R. R., \& Avdic, A. (2011). The Big Five Personality Traits, Learning Styles, and Academic Achievement. Personality and Individual Differences, 51(4), 472-477. https://doi.org/10.1016/j.paid.2011.04.019

Komarraju, M., Ramsey, A., \& Rinella, V. (2013). Cognitive and Non-Cognitive Predictors of College Readiness and Performance: Role of Academic Discipline. Learning and Individual Differences, 24(2013), 103-109. https://doi.org/10.1016/j.lindif.2012.12.007

Kuncel, N. R., Hezlett, S. A., \& Ones, D. S. (2004). Academic Performance, Career Potential, Creativity, and Job Performance: Can One Construct Predict them All? Journal of Personality and Social Psychology, 86(1), 148-161. https://doi.org/10.1037/0022-3514.86.1.148

Laidra, K., Pullmann, H., \& Allik, J. (2007). Personality and Intelligence as Predictors of Academic Achievement: A Cross-Sectional Study from Elementary to Secondary School. Personality and Individual Differences, 42(3), 441-451. https://doi.org/10.1016/j.paid.2006.08.001

Lozano, J. H., Gordillo, F., \& Pérez, M. A. (2014). Impulsivity, Intelligence, and Academic Performance: Testing the Interaction Hypothesis. Personality and Individual Differences, 61-62(2014), 63-68. https://doi.org/10.1016/j.paid.2014.01.013

Moreira, P. A. S., Dias, P., Vaz, F. M., \& Vaz, J. M. (2013). Predictors of Academic Performance and School Engagement-Integrating Persistence, Motivation and Study Skills Perspectives using Person-Centered and Variable-Centered Approaches. Learning and Individual Differences, 24(2013), 117-125. https://doi.org/10.1016/j.lindif.2012.10.016

Morris, P. E., \& Fritz, C. O. (2015). Conscientiousness and Procrastination Predict Academic Coursework Marks rather than Examination Performance. Learning and Individual Differences, 39(2015), 193-198. https://doi.org/10.1016/j.lindif.2015.03.007

Ng, P., Pinto, J., \& Williams, S. K. (2011). The Effects of Learning Styles on Course Performance: A Quantile Regression Analysis. Academy of Educational Leadership Journal, 15(1), 15-37.

Nyikahadzoi, L., Matamande, W., Taderera, E., \& Mandimika, E. (2013). Determinants of Students' Academic Performance in Four Selected Accounting Courses at University of Zimbabwe. Research in Higher Education Journal, 21, 1-9.

O’Connor, M. C., \& Paunonen, S. V. (2007). Big Five Personality Predictors of Post-Secondary Academic Performance. Personality and Individual Differences, 43(5), 971-990. https://doi.org/10.1016/j.paid.2007.03.017

Poropat, A. E. (2009). A Meta-Analysis of the Five-Factor Model of Personality and Academic Performance. Psychological Bulletin, 135(2), 322-338. https://doi.org/10.1037/a0014996

Robison, S., Jaggers, J., Rhodes, J., Blackmon, B. J., \& Church, W. (2017). Correlates of educational success: Predictors of school dropout and graduation for urban students in the Deep South. Children and Youth Services Review, 73, 37-46. https://doi.org/10.1016/j.childyouth.2016.11.031 
Romer, D. (1993). Do Students Go to Class? Should They? Journal of Economic Perspectives, 7(3), 167-174. https://doi.org/10.1257/jep.7.3.167

Rosander, P., \& Bäckström, M. (2012). The Unique Contribution of Learning Approaches to Academic Performance, after Controlling for IQ and Personality: Are there Gender Differences? Learning and Individual Differences, 22(6), 820-826. https://doi.org/10.1016/j.lindif.2012.05.011

Rosander, P., \& Bäckström, M. (2014). Personality Traits Measured at Baseline can Predict Academic Performance in Upper Secondary School Three Years Late. Scandinavian Journal of Psychology, 55(6), 611-618. https://doi.org/10.1111/sjop.12165

Rosander, P., Bäckström, M., \& Stenberg, G. (2011). Personality Traits and General Intelligence as Predictors of Academic Performance: A Structural Equation Modelling Approach. Learning and Individual Differences, 21(5), 590-596. https://doi.org/10.1016/j.lindif.2011.04.004

SIDS Action Platform. (2014). Sids Accelerated Modalities of Action. Retrieved from http://www.sids2014.org/samoapathway

Sirin, S. R. (2005). Socioeconomic Status and Academic Achievement: A Meta-Analytic Review of Research. Review of Educational Research, 75(3), 417-453. https://doi.org/10.3102/00346543075003417

Soares, D. L., Lemos, G. C., Primi, R., \& Almeida, L. S. (2015). The Relationship between Intelligence and Academic Achievement throughout Middle School: The Role of Students' Prior Academic Performance. Learning and Individual Differences, 41(2015), 73-78. https://doi.org/10.1016/j.lindif.2015.02.005

Spearman, C. (1928). The Abilities of Man. Science (New York, N.Y.), 68(1750), 38. https://doi.org/10.1126/science.68.1750.38-a

Tertiary Education Strategic Plan. (2013a). Tertiary Education Strategic Plan. Retrieved from http://www.maurice-info.mu/wp-content/uploads/2013/08/Strategic-Plan-Presentation-FINAL.pdf

Tinto, V. (1975). Dropout from Higher Education: A Theoretical Synthesis of Recent Research. Review of Educational Research, 45(1), 89-125. https://doi.org/10.3102/00346543045001089

United Nations. (1994). United Nations global conference on the sustainable development of Small Island Developing States. Retrieved from http://linkinghub.elsevier.com/retrieve/pii/0964569194900396

United Nations. (2005). Annex II Mauritius Strategy for the Further Implementation of the Programme of Action for the Sustainable Development of Small Island Developing States Contents. Retrieved from http://www.unesco.org/csi/B10/mim/mimStrategy_English.pdf

United Nations. (2011). Programme of action on the Least Developed Countries for the Decade 2011-2020.

Vanthournout, G. et al. (2012). Students' Persistence and Academic Success in a First-Year Professional Bachelor Program: The Influence of Students' Learning Strategies and Academic Motivation. Education Research International, 1-10. https://doi.org/10.1155/2012/152747

Vedel, A. (2014). The Big Five and Tertiary Academic Performance: A Systematic Review and Meta-Analysis. Personality and Individual Differences, 71(2014), 66-76. https://doi.org/10.1016/j.paid.2014.07.011

Vermunt, J. D., \& Vermetten, Y. J. (2004). Patterns in Student Learning: Relationships between Learning Strategies, Conceptions of Learning, and Learning Orientations. Educational Psychology Review, 16(4), 359-384. https://doi.org/10.1007/s10648-004-0005-y

Von Stumm, S., Hell, B., \& Chamorro-Premuzic, T. (2011). The Hungry Mind: Intellectual Curiosity is the Third Pillar of Academic Performance. Perspectives on Psychological Science, 6(6), 574-588. https://doi.org/10.1177/1745691611421204

Webb, E. (1915). Character and intelligence. British Journal of Psychology Monographs, I(3), 1-99.

Yip, M. C. W. (2012). Learning Strategies and Self-Efficacy as Predictors of Academic Performance: A

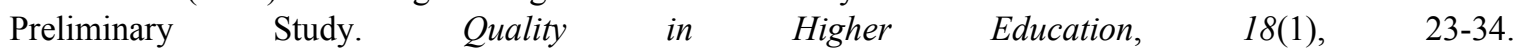
https://doi.org/10.1080/13538322.2012.667263

Yip, M. C. W. (2013). Learning Strategies and their Relationships to Academic Performance of high School Students in Hong Kong. Educational Psychology, 33(7), 817-827. https://doi.org/10.1080/01443410.2013.794493

Zuffianò, A., Alessandri, G., Gerbino, M., Kanacri, B. P. L., Giunta, L. D., Milioni, M., \& Caprara, G. V. (2013). Academic Achievement: The Unique Contribution of Self-Efficacy Beliefs in Self-Regulated Learning 
Beyond Intelligence, Personality Traits, and Self-Esteem. Learning and Individual Differences, 23(2012), 158-162. https://doi.org/10.1016/j.lindif.2012.07.010

\section{Copyrights}

Copyright for this article is retained by the author(s), with first publication rights granted to the journal.

This is an open-access article distributed under the terms and conditions of the Creative Commons Attribution license (http://creativecommons.org/licenses/by/4.0/). 